\title{
Can positive affect attenuate (persistent) pain? State of the art and clinical implications
}

\author{
Marjolein M. Hanssen ${ }^{1}$ • Madelon L. Peters ${ }^{1}$ • Jantine J. Boselie ${ }^{1}$ • Ann Meulders ${ }^{1,2}$
}

Published online: 9 November 2017

(C) The Author(s) 2017. This article is an open access publication

\begin{abstract}
Purpose of Review Pain is an intense experience that can place a heavy burden on peoples' lives. The identification of psychosocial risk factors led to the development of effective pain treatments. However, effect sizes are modest. Accumulating evidence suggests that enhancing protective factors might also impact on (well-being despite) pain. Recent findings on positive affect (interventions) towards pain-related outcomes will be reviewed, and new avenues for treatment of persistent pain will be discussed.

Recent Findings Positive affect significantly attenuates the experience of pain in healthy and clinical populations. Positive affect interventions effectively reduce pain sensitivity and bolster well-being despite pain. Through both psychological and (neuro-)biological pathways, but also through its effect on central treatment processes such as inhibitory learning, positive affect can optimize the efficacy of existing treatments.
\end{abstract}

This article is part of the Topical Collection on Chronic Pain

Ann Meulders

ann.meulders@maastrichtuniversity.nl

Marjolein M. Hanssen

m.hanssen@maastrichtuniversity.nl

Madelon L. Peters

madelon.peters@maastrichtuniversity.nl

Jantine J. Boselie

jantine.boselie@maastrichtuniversity.nl

1 Clinical Psychological Science, Research Group Behavioral Medicine, Maastricht University, P.O. 616, 6200

MD Maastricht, The Netherlands

2 Research Group Health Psychology, KU Leuven, Leuven, Belgium
Summary Comprehensive understanding of the unique roles and dynamic interplay of positive and negative affect in moderating pain may optimize the treatment of (persistent) pain.

Keywords Positive affect $\cdot$ Positive psychology interventions $\cdot$ Persistent pain $\cdot$ Resilience $\cdot$ Pain

\section{Introduction}

Pain is a complex experience that may lead to various limitations in daily life [1]. According to the International Association for the Study of Pain [2], pain is "an unpleasant sensory and emotional experience associated with actual or potential tissue damage." This definition emphasizes that pain is in essence both a sensory and an emotional experience for which tissue damage is not a prerequisite. Several decades of pain research support a biopsychosocial conceptualization in which pain is a result of the interplay between biological, psychological, and social factors [3-5]. For instance, it has been shown that pain-related fear can be even more disabling than pain itself [6]. The identification of psychological factors that negatively influence the experience of pain led to the development of effective psychological pain treatments aimed at reducing overly negative cognitions/emotions and maladaptive behaviors. However, a subset of patients does not complete such a treatment or fails to achieve satisfactory results during or after the treatment [7-9]. Thus, there is considerable room for improvement in psychological pain treatment targeting risk factors for increased suffering due to persistent pain.

In pain psychology, as in other areas of clinicalpsychological and psychiatric research, the exclusive focus on individual vulnerabilities ("fixing what's wrong") is recently being extended with an interest in what protects people in 
challenging circumstances ("building what's strong”) [10,11]. Resilient individuals, described as individuals who flexibly adapt to adverse circumstances (e.g., individuals who successfully deal with the limitations accompanying persistent pain) have become a source of inspiration in (pain) psychology [12, 13]. Sturgeon and Zautra [14] argued for systematic research of resources/mechanisms of both vulnerability and resilience to disentangle what leads to outcomes of recovery (return to homeostasis), sustainability (enduring engagement in valued activities), and growth (benefit finding/post-traumatic growth) in the field of pain. Evidence for positive affect as a resilience factor in pain has accumulated $[15 \bullet \bullet, 16 \bullet \cdot]$. Moreover, interventions based on positive psychology, or the study of positive human functioning [17], can diminish pain intensity and promote positive affect and well-being despite pain [18• 19]. In what follows, we will review the recent developments after a brief conceptualization of the construct "affect" is given.

\section{Positive Affect: a Conceptualization}

The term "affect" refers to both short-lasting emotions as well as more stable moods. While an emotion is an affective state that has a clear focus (response to specific events), moods are more diffuse [20,21].

Affective states are considered to vary along several dimensions $[20,22]$. First, the dimension of valence indicates the subjective evaluation of an experienced state. While positive affect reflects pleasant feelings (e.g., joy, amusement), negative affect reflects unpleasant feelings (e.g., fear, anger) [23]. Second, the dimension of arousal refers to the activation of the sympathetic nervous system in response to an event, generally experienced as (high/low) levels of energy. In response to threat, increased activity in the sympathetic nervous system triggers physiological hyperarousal, also known as the fight-flight response [24]. The level of arousal is immediately linked to motivation. Third, the motivational component of emotions refers to the action tendencies that accompany emotions. Today, it is widely accepted that action tendencies, such as escape in response to fear or approach behavior in response to enthusiasm, is what makes emotions evolutionary adaptive [20-22]. The adaptive nature of emotions materializes in the way they control attention, thoughts, and behavior. For instance, emotions in response to pain guide pain-related thoughts, interrupt ongoing behavior, and disengage attention from stimuli other than pain. In case of acute pain, this narrowing effect of negative emotions has a protective function. When affective states are very intense or prolonged, however, they might exceed their evolutionary function of promoting adaptation. This undesirable side effect is often observed in patients with persistent pain in which adaptation is compromised as a result of misdirected attempts to control or avoid pain $[25 \bullet, 26]$.
A substantial part of the literature on affect has been dedicated to clarifying the structure of the construct. Both bipolar and bifactorial models have been proposed as a framework for positive and negative affect. On the one hand, it was found that decreases in negative affective states associated with pain coincide with increased positive affect, hereby supporting the bipolar conceptualization [27]. On the other hand, evidence also exists supporting the bifactorial model, that is, certain positive (or negative) events seem to bring about changes in positive (or negative) affect only [28]. In a recent review on positive affect and pain, Finan and Garland [16••] concluded that positive affect and negative affect are only moderately correlated both in healthy participants following experimental pain induction and in chronic pain patients. According to the Dynamic Model of Affect [29, 30], both conceptualizations are useful in describing daily fluctuations in affect, depending on the circumstances. While positive affect and negative affect tend to show modest correlations under normal circumstances, they may be highly correlated in adverse situations (e.g., a pain flare up). In this view, resilience may reflect the ability to maintain high levels of positive affect despite elevations in negative affect [30,31]. Although positive affect and negative affect might show substantial overlap under certain conditions, they seem to be separable affective states that have unique roles in modulating the experience of pain.

\section{Positive Affect as a Resilience Factor for (Persistent) Pain}

The role of negative emotions in the experience of pain is well-documented $[32,33]$. Negative emotional responses or low mood states, such as anger or depression, can intensify the pain experience [34-36]. The role of pain-related fear in particular has been emphasized in acute $[37,38]$ as well as in chronic pain [26,39]. Fear and anxiety—in case of mild levels and when limited in time - actually instigate recovery behaviors. However, when intense or prolonged in time, these emotions instigate a downward spiral, which in turn may complicate the experience of persistent pain. More specifically, fearavoidance patterns have been shown to predate future depressive feelings, pain disability, and disuse in the long run [25, 26]. For example, fear of falling correlates significantly with foot impairment, foot disability, and walking velocity in women with established rheumatoid arthritis [40].

Evidence for the role of positive affect in the experience of pain is accumulating. In contrast to the typical pain-enhancing role of negative affect, positive affect seems to be related to diminished pain [31, 41]. Moreover, positive affect enhances adaptation to persistent pain as exemplified by its negative associations with pain intensity, negative affect, sleep disturbances, and physical dysfunctions in pain patients [42-44]. Positive affect was also found to buffer the negative effects 
of pain on general functioning and well-being in patients with rheumatoid arthritis [31, 45] and other persistent pain conditions [31, 46].

Experimental work confirms the causal role of positive affect towards pain-related outcomes. Generally, it is found that successfully inducing positive affect using for instance affective slides/pictures/video fragments leads to a less intense pain experience than inducing negative or neutral affect in healthy participants undergoing an experimental pain task $[47,48]$. In addition, experimentally inducing positive affect (and cognitions) by means of writing and visualizing about a future in which most life goals have been accomplished (Best Possible Self (BPS) exercise) led not only to reduced pain sensitivity [49] but also to less pain-induced cognitive interference in healthy participants $[50,51]$. Particularly positive emotions with moderate to high levels of arousal (e.g., joy, happiness) seem to be able to produce this effect [52].

The BPS exercise is an example of a Positive Psychology Intervention (PPI), a psychological intervention (training/exercise/therapy) aimed at cultivating positive emotions, cognitions, and behavior [53]. These PPIs also proved to be associated with pain-related outcomes in (sub-)clinical populations. For instance, Hausmann and colleagues [19] performed secondary analyses on a subset of a community sample that participated in an online positive psychology program comprising several exercises (e.g., practicing gratitude or identifying strengths). The intervention led to increased positive mood and reduced bodily pain at the end of the 6-week interventions and at a 6-month follow-up in the individuals reporting current pain.

Another computer-based PPI also proved to be successful for individuals with physical disability and chronic pain [54]. Reduced levels of several pain outcomes (pain intensity, pain interference, and depressive feelings) were recorded post intervention and at a 2.5-month follow-up. Carson and colleagues [55] found that an 8-week program focusing on one specific exercise, "practicing kindness," also led to improvements in pain and distress in chronic low back pain patients. In a large-scale randomized clinical trial (RCT), an 8-week online PPI "Happy despite Pain" consisting of four modules (self-compassion, "three good things," savoring, and the BPS exercise) was compared to a risk-based cognitive-behavioral intervention in a sample predominantly consisting of fibromyalgia patients. Although no reduction in pain intensity was reported, both active interventions effectively reduced depression and increased happiness in contrast to individuals in the waiting list control group, who reported no significant changes [18•].

The benefits of inducing positive affect on pain-related outcomes were also confirmed in pain patients receiving PPIs using modern technology. For instance, a text messagebased social support intervention succeeded in increasing positive affect and reducing perceptions of pain and pain interference in chronic non-cancer pain patients [56]. Additionally, Herrero and colleagues used virtual reality (VR) to induce positive affect in fibromyalgia patients. A predefined positive nature scenario was projected in the VR surrounding, including music with positive valence and high arousal. This VR intervention was successful in improving quality of life and reducing negative emotions as well as dysfunctional coping strategies [57]. Thus, ample evidence, also in (sub-)clinical populations, endorses the causal role of positive affect in reducing undesirable pain-related outcomes.

\section{Pathways of Positive Affect Towards Pain-Related Outcomes}

\section{A (Neuro)Biological Pathway}

Biological processes have been suggested to explain healthpromoting effects of positive affect [58]. Nervous, endocrine, and immune processes play a role in the experience of (persistent) pain, which is typically intertwined with a complex stress response. Without providing an exhaustive description of biological processes in (persistent) pain, relevant connections with positive affect are highlighted below.

First, processing of nociceptive stimuli involves several key brain regions, including areas associated with emotional processes [59]. Persistent pain may be accompanied by structural alternation in (the connectivity of) key regions such as the prefrontal cortex or limbic structures $[60,61]$. In addition, brain regions processing sensory, emotional, and cognitive information are involved in descending modulation of pain [62]. Positive affect has been related to both spinal and supraspinal pain modulation. For instance, inducing positive affect by means of emotional pictures was associated with a decrease in spinal nociceptive reflex, an index of descending pain modulation [63]. A study by Roy and colleagues showed that a positive affect induction modulates pain through multiple mechanisms, including supraspinal modulation [64].

Second, nociception is typically accompanied by a stress response (i.e., increase in cortisol), aimed at coping with the injury. Persistent exposure to stressors can lead to maladaptive neurobiological changes in pain processing pathways, in particular the descending inhibitory pain pathway, resulting in enhanced pain sensitivity (i.e., stress-induced hyperalgesia) [65]. Typically, an inverse relationship between positive affect and levels of cortisol has been found. This link seems to be independent from levels of negative affect [66].

Third, effects of pro-inflammatory cytokines are often observed in conditions of persistent pain such as osteoarthritis. Pro-inflammatory cytokines not only sensitize peripheral nerve fibers [67], but also lead to centrally maintained hyperalgesic states $[68,69]$. It seems that positive affect may attenuate both peripheral and central pain facilitation through 
a reduction of inflammation [58]. Recent evidence however also shows that inflammation might modulate the mesolimbic reward system, hereby impacting on the responsiveness to pleasurable stimuli [70].

These findings thus suggest that positive affect may influence nervous, endocrine, and immune responses, as well as their complex interplay in relation to the experience of pain.

\section{A Pathway Through Countering Fear-Avoidance Patterns}

Positive affect may prevent individuals from getting caught in a downward spiral that fuels negative pain-related outcomes. Based on the (partial) overlap with negative affect, positive affect might prevent that individuals adopt fear-avoidance patterns that promote maladjustment to pain. Additionally, the unique characteristics of positive affect may also fuel a positive upward spiral bolstering positive adaptation to persistent pain. More specifically, the broadening effect of positive emotions as described in the Broaden-and-Built theory can counter the narrowing effect of negative emotions [29, 71].

The Broaden-and-Built Model of Fredrickson is one of the most influential theories that have been introduced to explain the beneficial effects of positive emotions [72, 73]. Central to this model is the broadening effect of positive emotions on attention, thoughts, and behavior. In the long run, the broadening effect of positive emotions contributes to building enduring physical, cognitive, and social resources. The "undoing hypothesis" explains how long-term positive effects of positive emotions can serve as an antidote against the immediate effects of negative emotions [71]. Reduced positive emotions that might result from the experience of pain may increase the vulnerability to further negative emotions. Experimental and clinical work provides evidence for the protective role of positive affect in persistent pain based on its potential to broaden attention, cognition, and behavior.

First, experimental work shows that positive affect broadens the scope of (visual) attention [73, 74]. Attentional biases for negative stimuli or hypervigilance for pain are often found in patients with persistent pain [75]. Positive affect may counter the narrowing effect of fear on attention. For instance, positive affect may help patients with rheumatoid arthritis to not only be focused on pain and its negative consequences but also to be attentive for positive aspects of the situation and/or for non-pain-related stimuli, a pattern associated with better adjustment to pain $[25,26]$.

Second, positive emotions can buffer negative pain-related cognitions, such as pain catastrophizing. For instance, inducing positive emotions in healthy participants led to lower pain reports in an experimental pain task through diminished levels of pain catastrophizing [49]. The positive psychology intervention "Happy despite Pain" also significantly impacted on the level of pain catastrophizing in patients with persistent pain $[18,76]$. Increases in positive emotions might particularly decrease catastrophic thoughts because they reduce ruminating and feeling helpless [15••]. In addition, positive emotions might promote positive and neutral (re-)appraisal processes related to pain. A positive (non-negative) appraisal style has been advanced as a key mechanism in resilience to adverse stimuli such as pain [11].

Third, positive affect might reduce engaging rigidly in specific action tendencies and create behavioral flexibility [21, 71]. While negative affect in response to pain leads to action tendencies primarily aimed at avoiding pain or reinjury, positive affect enhances (continued) engagement in valued activities despite the experience of pain. White and colleagues [77] observed significantly higher daily activity as measured by the number of steps in knee osteoarthritis patients with high positive affect as opposed to low positive affect. The number of steps in patients with high positive affect did not depend on their pain levels. Additionally, a VR study in fibromyalgia patients showed that inducing positive affect leads to enhanced activity engagement and motivation [57].

\section{A Pathway Through Improved Learning}

The ability to accurately predict pain urges us to take action and protect ourselves from impending or actual bodily threat. Pavlovian (or classical) conditioning is the prime mechanism enabling us to predict (increases in) pain [78]. More specifically, an initially neutral stimulus (conditioned stimulus; CS) that has preceded or co-occurred with pain (unconditioned stimulus; US) may come to elicit fear and spur avoidance behavior (conditioned response; CR) [79]. Accurately identifying unique predictors of pain is challenging, because typically multiple environmental stimuli as well as interoceptive and proprioceptive events are present during a pain episode. Failure to identify the actual predictors of pain may lead to the spreading of fear and threat beliefs to a wide range of stimuli that were present during the pain experience, resulting in sustained anxiety [80, 81], and/or an increase in the frequency of fearful responding and persistent avoidance behavior. It is commonly accepted that threat expectancy learning (awareness of the CS-US contingency) is necessary to generate conditioned fear (i.e., arousal component of fear) and avoidance behavior (i.e., behavioral component of fear). Accumulating evidence shows that patients with persistent pain display impaired safety learning and excessive generalization [82-85]. There is preliminary experimental evidence suggesting that increasing positive affect may alter at least two learning processes: generalization and extinction (inhibitory) learning.

First, positive affect may limit excessive generalization of pain-related fear. Inducing positive affect in healthy individuals using the BPS exercise protected against generalization of fear to technically safe stimuli [86•]. More specifically, in a learning task, in which one movement was conditioned to elicit fear (by repeatedly pairing it with a painful 
electrocutaneous stimulus) and another movement was not. Novel movements (generalization stimuli, GSs) with varying levels of similarity with the original movements were subsequently tested. Results showed that positive affect especially decreased fear for those GS movements that were more similar to the original non-painful movement. Generalization is an adaptive process, enabling us to extrapolate the threat value from one situation to a similar one; excessive generalization to technically safe stimuli however may be maladaptive and lead to persistent avoidance behavior. Positive affect seems to leave the adaptive side of generalization intact, but eliminates maladaptive "overgeneralization."

Second, it has been argued that positive affect might enhance a central treatment process, namely inhibitory learning [87••]. Pavlovian extinction learning is the laboratory analogue of clinical exposure treatment. Nowadays, extinction learning is not viewed as erasing the originally acquired association (e.g., a bending movement $\rightarrow$ pain; CSUS association), but the learning of a new association (e.g., a bending movement $\rightarrow$ no pain; CS-noUS association) that inhibits the behavioral expression of the first-learned association. Therefore, this type of learning is also referred to as inhibitory learning. Exposure therapy has a strong pedigree as one of the most effective strategies to reduce pain-related fear and associated disabling behaviors in highly fearful chronic pain patients [88]. In practice, patients are asked to perform feared activities (e.g., bending to pick something up) without the feared catastrophe occurring (e.g., the spine snapping). This disconfirmation experience allows the patient to learn that these activities are actually safe (i.e., safety learning). Gradually, this new learning will reduce catastrophic thoughts, pain-related fear, and functional disability [25], and although not an explicit goal before treatment, it often reduces pain as well. Experimental evidence is emerging to support the notion that positive affect may enhance inhibitory learning. For example, trait-positive affect has been shown to protect against deficient safety learning during extinction in healthy high-anxious individuals [89]. Moreover, experimental work also shows that positive affect might prevent fear that was successfully extinguished from returning post treatment $[90,91]$.

Increasing positive affect in chronic pain patients thus may have beneficial effects through limiting excessive spreading of pain-related fear and avoidance as well as through the optimization of (inhibitory) learning processes during treatment.

\section{Clinical Implications}

In recent decades, efforts have been devoted to enhance positive affect in order to bolster its protective function. Meta- analyses demonstrated the overall effectiveness of a variety of positive psychology interventions on general well-being in healthy populations $[53,92]$. The bulk of literature clearly suggests that many of these interventions are successful in inducing positive affect in individuals with pain complaints resulting in pain reduction or improved well-being despite pain [e.g., [18•, 19]. PPIs can be used effectively as standalone exercises [93-95] or combined in a positive psychology package [54]. Interestingly, administration of PPIs via online platforms, text message, or VR also generates promising results $[18 \bullet, 19,54]$. Methods of administration of PPIs seem limitless, and they offer the possibility to provide a low-cost internet-based treatment with or without guidance of a therapist [18•, 19, 54].

Positive interventions have been found to be a worthy alternative for the gold standard in pain treatment, cognitive-behavior therapy [18•]. However, since positive and negative affect may have unique roles in modulating the experience of pain $[16 \bullet \bullet, 29,30]$, a treatment combining insights from both research areas may have additional benefits. This combination can be found in recent acceptance-based cognitive-behavioral treatments, in which both cognitive-behavioral techniques and elements from positive psychology are included. Preliminary evidence in depressive individuals indicates that positive affect might be one of the mediating processes leading to greater well-being and less depressive feelings following such an acceptance-based cognitive-behavioral treatment [96]. Veehof and colleagues [97] concluded that acceptance-based cognitive-behavioral treatments and traditional cognitive-behavioral treatments show comparable results in the treatment of chronic pain. Research should therefore aim at further exploring the differential effects of positive and negative emotions in order to maximize existing pain treatments.

Although cognitive-behavioral exposure treatments have proven successful, not all patients benefit from it equally and clinical practice definitely faces certain challenges. For instance, it seems the treatment may be too demanding/unpleasant for some patients. Additionally, fear is not reduced sufficiently in all patients by the end of the treatment or returns after a successful therapeutic trajectory [7-9]. Positive affect may help to tackle some of the challenges faced in the treatment of pain patients. First and most importantly, positive affect may enhance learning processes, leading to faster and more profound extinction of pain-related fear [87••]. Second, positive affect might fuel positive cognitions such as positive expectations regarding treatment outcomes. The impact of patients' expectations for recovery on actual treatment success has repeatedly received support [98]. Following predictions from the expectancy-value model of motivation, confidence regarding the attainability of a desired goal (e.g., treatment goal) fosters action and continued effort towards this goal [99]. Third, positive affect may therefore also enhance 
motivation and treatment adherence, which are important predictors of the success of exposure treatments [100]. In clinical practice, it is well known that motivating patients to expose themselves to feared movements (that initially might even increase pain) during the sessions and in everyday life is challenging yet necessary.

Thus, the use of PPIs in clinical practice definitely offers a myriad of possibilities. PPIs are effective and could easily be introduced in any treatment to enhance treatment effects or to prevent dropout (by means of shaping participants' motivation or treatment expectations). Moreover, access to positive psychology prior to, during, or post intervention might offer solutions to problems such as long waiting lists, passive treatment participation, or difficulties to maintain long-term treatment effects.

\section{Conclusion}

Only recently, attention has grown for the role of protective factors in (pain) psychology [14, 15••]. Evidence has accumulated that not only negative affect but also positive affect might play a substantial role in determining pain patients' well-being [16••, 32]. Evidence supporting positive affect as a resiliency factor for chronic pain is expanding. Not only does positive affect lead to lower pain intensity ratings and higher pain tolerance [32, 52], it also diminishes pain disability and improves quality of life [31, $42,46]$. Interventions enhancing positive affect have been shown to reduce pain and improve the well-being of pain patients [e.g., $18 \bullet, 19]$. Moreover, it has been suggested that enhancing positive affect may have the potential to optimize treatment efficacy of existing pain treatments [87••]. Comprehensive understanding of both risk and resilience factors for pain on processes involved in pain and in the treatment of pain might lead to most effective combined strategies in clinical practice.

\section{Compliance with ethical standards}

Conflict of Interest Ann Meulders is a postdoctoral researcher of the Research Foundation Flanders (FWO-Vlaanderen), Belgium (grant ID: $12 \mathrm{E} 3717 \mathrm{~N}$ ), and is also supported by a Vidi grant from the Netherlands Organization for Scientific Research (NWO), the Netherlands (grant ID: 452-17-002). Marjolein M. Hanssen, Madelon L. Peters, Jantine J. Boselie, and Ann Meulders declare that they have no conflict of interest.

Human and Animal Rights and Informed Consent This article concerns a review of the literature and as such does not contain previously unpublished studies with human or animal subjects performed by any of the authors. Compliance with ethical standards thus has been declared in the respective original publications.

Open Access This article is distributed under the terms of the Creative Commons Attribution 4.0 International License (http:// creativecommons.org/licenses/by/4.0/), which permits unrestricted use, distribution, and reproduction in any medium, provided you give appropriate credit to the original author(s) and the source, provide a link to the Creative Commons license, and indicate if changes were made.

\section{References}

Papers of particular interest, published recently, have been highlighted as:

- Of importance

• Of major importance

1. Breivik H, Collett B, Ventafridda V, Cohen R, Gallacher D. Survey of chronic pain in Europe: prevalence, impact on daily life, and treatment. Eur J Pain. 2006;10(4):287-333. https://doi. org/10.1016/j.ejpain.2005.06.009.

2. IASP Task Force on Taxonomy CoCP. Part 3: pain terms, a current list with definitions and notes of usage. In: Merksey H, Bogduk N, editors. Classification of chronic pain. Seattle: IASP Press; 1994.

3. Engel GL. From biomedical to biopsychosocial. Being scientific in the human domain. Psychosomatics. 1997;38:521-8.

4. Gatchel RJ, Peng YB, Peters ML, Fuchs PN, Turk DC. The biopsychosocial approach to chronic pain: scientific advances and future directions. Psychol Bull. 2007;133(4):581-624. https://doi.org/10.1037/0033-2909.133.4.581.

5. Waddell G. The biopsychosocial model. In: Waddell G, editor. The back pain revolution. Edinburgh: Churchill Livingston; 2004. p. 265-82.

6. Crombez G, Vlaeyen JW, Heuts PH, Lysens R. Pain-related fear is more disabling than pain itself: evidence on the role of pain-related fear in chronic back pain disability. Pain. 1999;80(1-2):329-39.

7. Morley S, Williams A, Eccleston C. Examining the evidence about psychological treatments for chronic pain: time for a paradigm shift? Pain. 2013;154(10):1929-31. https://doi.org/10.1016/ j.pain.2013.05.049.

8. Arch JJ, Craske MG. First-line treatment: a critical appraisal of cognitive behavioral therapy developments and alternatives. The Psychiatric Clinics of North America. 2009;32(3):525-47. https:// doi.org/10.1016/j.psc.2009.05.001.

9. Craske MG, Mystkowski JL. Exposure therapy and extinction: clinical studies. In: Craske MG, Hermans D, Vansteenwegen D, editors. Fear and learning: from basic processes to clinical implications. Washington DC, US: American Psychological Association; 2006

10. Masten AS, Reed MJ. Resilience in development. In: Snyder CR, Lopez SJ, editors. The handbook of positive psychology. New York, NY: Oxford University Press; 2002.

11. Kalisch R, Müller MB, Tüscher O. A conceptual framework for the neurobiological study of resilience. Behav Brain Sci. 2014;38 https://doi.org/10.1017/S0140525X1400082X.

12. Karoly P, Ruehlman LS. Psychological "resilience" and its correlates in chronic pain: findings from a national community sample. Pain. 2006;123(1-2):90-7. https://doi.org/10.1016/j.pain.2006. 02.014 .

13. Mancini AD, Bonanno GA. Predictors and parameters of resilience to loss: toward an individual differences model. J Pers. 2009;77(6):1805-32. https://doi.org/10.1111/j.1467-6494.2009. 00601.x.

14. Sturgeon JA, Zautra AJ. Resilience: a new paradigm for adaptation to chronic pain. Curr Pain Headache Rep. 2010;14(2):10512. https://doi.org/10.1007/s11916-010-0095-9.

15.• Ong AD, Zautra AJ, Reid MC. Chronic pain and the adaptive significance of positive emotions. Am Psychol. 2015;70(3):2834. https://doi.org/10.1037/a0038816. Provides a clear rationale for considering the role of positive affect towards pain.

16.• Finan PH, Garland EL. The role of positive affect in pain and its treatment. Clin J Pain. 2015;31(2):177-87. https://doi.org/10. 1097/AJP.0000000000000092. Recent review on positive (versus negative) affect and pain. 
17. Seligman ME, Csikszentmihalyi M. Positive psychology. An introduction. Am Psychol. 2000;55(1):5-14.

18. Peters ML, Smeets E, Feijge M, van Breukelen G, Andersson G, Buhrman M, et al. Happy despite pain: a randomized controlled trial of an 8-week internet delivered positive psychology intervention for enhancing well-being in patients with chronic pain. Clinical Journal of Pain. 2017; 33(11):962-975. https://doi.org/ 10.1097/AJP.0000000000000494. RCT providing evidence for online positive psychology intervention for pain.

19. Hausmann LR, Parks A, Youk AO, Kwoh CK. Reduction of bodily pain in response to an online positive activities intervention. J Pain. 2014;15(5):560-7. https://doi.org/10.1016/j.jpain.2014.02.004.

20. Frijda NH. The emotions. Cambridge University Press; 1986.

21. Fredrickson B. Positive emotions. In: Snyder CR, Lopez SJ, editors. Handbook of positive psychology. New York: Oxford University Press; 2005. p. 120-34.

22. Frijda NH, Mesquita B. The analysis of emotions: Dimensions of variation. In: Mascolo MF, Griffin S, editors. What develops in emotional development? New York: Plenum Press; 1998. p. 273-95.

23. Clore GL, Huntsinger JR. How emotions inform judgment and regulate thought. Trends Cogn Sci. 2007;11(9):393-9. https:// doi.org/10.1016/j.tics.2007.08.005.

24. Cannon W. Wisdom of the body. United States: W. W. Norton and Company; 1932.

25. Vlaeyen JW, Crombez G, Linton SJ. The fear-avoidance model of pain. Pain. 2016;157(8):1588-9. https://doi.org/10.1097/j.pain. 0000000000000574 . Overview and update of leading biopsychosocial model in the study of (persistent) pain.

26. Vlaeyen JW, Linton SJ. Fear-avoidance and its consequences in chronic musculoskeletal pain: a state of the art. Pain. 2000;85(3): 317-32.

27. Lefebvre JC, Keefe FJ, Affleck G, Raezer LB, Starr K, Caldwell DS, et al. The relationship of arthritis self-efficacy to daily pain, daily mood, and daily pain coping in rheumatoid arthritis patients. Pain. 1999;80(1-2):425-35.

28. Gable SL, Reis HT, Elliot AJ. Behavioral activation and inhibition in everyday life. J Pers Soc Psychol. 2000;78(6):1135-49.

29. Zautra AJ, Affleck GG, Tennen H, Reich JW, Davis MC. Dynamic approaches to emotions and stress in everyday life: Bolger and Zuckerman reloaded with positive as well as negative affects. J Pers. 2005;73(6):1511-38. https://doi.org/10.1111/j. 0022-3506.2005.00357.x.

30. Davis MC, Zautra AJ, Smith B. Chronic pain, stress, and the dynamics of affective differentiation. J Pers. 2004;72(6):113359. https://doi.org/10.1111/j.1467-6494.2004.00293.x.

31. Zautra AJ, Johnson LM, Davis MC. Positive affect as a source of resilience for women in chronic pain. J Consult Clin Psychol. 2005;73(2):212-20. https://doi.org/10.1037/0022-006x.73.2.212.

32. Wiech K, Tracey I. The influence of negative emotions on pain: behavioral effects and neural mechanisms. NeuroImage. 2009;47(3):987-94. https://doi.org/10.1016/j.neuroimage.2009. 05.059 .

33. Janssen SA. Negative affect and sensitization to pain. Scand J Psychol. 2002;43(2):131-7.

34. Strigo IA, Simmons AN, Matthews SC, Craig AD, Paulus MP. Association of major depressive disorder with altered functional brain response during anticipation and processing of heat pain. Arch Gen Psychiatry. 2008;65(11):1275-84. https://doi.org/10. 1001/archpsyc.65.11.1275.

35. van Middendorp H, Lumley MA, Jacobs JW, Bijlsma JW, Geenen R. The effects of anger and sadness on clinical pain reports and experimentally-induced pain thresholds in women with and without fibromyalgia. Arthritis Care \& Research. 2010;62(10):1370 6. https://doi.org/10.1002/acr.20230.

36. Burns JW, Gerhart JI, Bruehl S, Peterson KM, Smith DA, Porter LS, et al. Anger arousal and behavioral anger regulation in everyday life among patients with chronic low back pain: relationships to patient pain and function. Health Psychology : Official Journal of the Division of Health Psychology, American Psychological Association. 2015;34(5):547-55. https://doi.org/ 10.1037/hea0000091.

37. Hirsh AT, George SZ, Bialosky JE, Robinson ME. Fear of pain, pain catastrophizing, and acute pain perception: relative prediction and timing of assessment. J Pain. 2008;9(9):806-12. https://doi. org/10.1016/j.jpain.2008.03.012.

38. van Wijk AJ, Hoogstraten J. Anxiety and pain during dental injections. J Dent. 2009;37(9):700-4. https://doi.org/10.1016/j. jdent.2009.05.023.

39. Leeuw M, Goossens ME, Linton SJ, Crombez G, Boersma K, Vlaeyen JW. The fear-avoidance model of musculoskeletal pain: current state of scientific evidence. J Behav Med. 2007;30(1):7794. https://doi.org/10.1007/s10865-006-9085-0.

40. Morpeth T, Brenton-Rule A, Carroll M, Frecklington M, Rome K. Fear of falling and foot pain, impairment and disability in rheumatoid arthritis: a case-control study. Clin Rheumatol. 2016;35(4): 887-91. https://doi.org/10.1007/s10067-015-3124-6.

41. Finan PH, Quartana PJ, Smith MT. Positive and negative affect dimensions in chronic knee osteoarthritis: effects on clinical and laboratory pain. Psychosom Med. 2013;75(5):463-70. https://doi. org/10.1097/PSY.0b013e31828efld6.

42. Song S, Graham-Engeland JE, Mogle J, Martire LM. The effects of daily mood and couple interactions on the sleep quality of older adults with chronic pain. J Behav Med. 2015;38(6):944-55. https://doi.org/10.1007/s10865-015-9651-4.

43. Huber A, Suman AL, Biasi G, Carli G. Predictors of psychological distress and well-being in women with chronic musculoskeletal pain: two sides of the same coin? J Psychosom Res. 2008;64(2): 169-75. https://doi.org/10.1016/j.jpsychores.2007.09.005.

44. Connelly M, Keefe FJ, Affleck G, Lumley MA, Anderson T, Waters S. Effects of day-to-day affect regulation on the pain experience of patients with rheumatoid arthritis. Pain. 2007;131(12):162-70. https://doi.org/10.1016/j.pain.2007.01.002.

45. Strand EB, Zautra AJ, Thoresen M, Odegard S, Uhlig T, Finset A. Positive affect as a factor of resilience in the pain-negative affect relationship in patients with rheumatoid arthritis. J Psychosom Res. 2006;60(5):477-84. https://doi.org/10.1016/j.jpsychores. 2005.08.010.

46. Thong ISK, Tan G, Jensen MP. The buffering role of positive affect on the association between pain intensity and pain related outcomes. Scand J Pain. 2017;14:91-7. https://doi.org/10.1016/j. sjpain.2016.09.008.

47. Silvestrini N, Piguet V, Cedraschi C, Zentner MR. Music and auditory distraction reduce pain: emotional or attententional effects? Music and Medicine. 2011;3:264-70.

48. Rhudy JL, Williams AE, McCabe KM, Russell JL, Maynard LJ. Emotional control of nociceptive reactions $(\mathrm{ECON})$ : do affective valence and arousal play a role? Pain. 2008;136(3):250-61. https://doi.org/10.1016/j.pain.2007.06.031.

49. Hanssen MM, Peters ML, Vlaeyen JW, Meevissen YM, Vancleef LM. Optimism lowers pain: evidence of the causal status and underlying mechanisms. Pain. 2013;154(1):53-8. https://doi.org/ 10.1016/j.pain.2012.08.006.

50. Boselie JJ, Vancleef LM, Peters ML. Increasing optimism protects against pain-induced impairment in task-shifting performance. J Pain. 2017;18(4):446-55. https://doi.org/10.1016/j.jpain.2016.12. 007.

51. Boselie JJ, Vancleef LM, Smeets T, Peters ML. Increasing optimism abolishes pain-induced impairments in executive task performance. Pain. 2014;155(2):334-40. https://doi.org/10.1016/j. pain.2013.10.014.

52. Rhudy JL, Meagher MW. The role of emotion in pain modulation. Current Opinion in Psychiatry. 2001;14(3):241-5. 
53. Sin NL, Lyubomirsky S. Enhancing well-being and alleviating depressive symptoms with positive psychology interventions: a practice-friendly meta-analysis. J Clin Psychol. 2009;65(5):46787. https://doi.org/10.1002/jclp.20593.

54. Muller R, Gertz KJ, Molton IR, Terrill AL, Bombardier CH, Ehde $\mathrm{DM}$, et al. Effects of a tailored positive psychology intervention on well-being and pain in individuals with chronic pain and a physical disability: a feasibility trial. Clin J Pain. 2016;32(1):32-44. https://doi.org/10.1097/AJP.0000000000000225.

55. Carson JW, Keefe FJ, Lynch TR, Carson KM, Goli V, Fras AM, et al. Loving-kindness meditation for chronic low back pain: results from a pilot trial. J Holist Nurs. 2005;23(3):287-304. https:// doi.org/10.1177/0898010105277651.

56. Guillory J, Chang P, Henderson CR Jr, Shengelia R, Lama S, Warmington $\mathrm{M}$, et al. Piloting a text message-based social support intervention for patients with chronic pain: establishing feasibility and preliminary efficacy. Clin J Pain. 2015;31(6):548-56. https:// doi.org/10.1097/AJP.0000000000000193.

57. Herrero R, Garcia-Palacios A, Castilla D, Molinari G, Botella C. Virtual reality for the induction of positive emotions in the treatment of fibromyalgia: a pilot study over acceptability, satisfaction, and the effect of virtual reality on mood. Cyberpsychology, Behavior and Social Networking. 2014;17(6):379-84. https:// doi.org/10.1089/cyber.2014.0052.

58. Steptoe A, Dockray S, Wardle J. Positive affect and psychobiological processes relevant to health. J Pers. 2009;77(6):1747-76. https://doi.org/10.1111/j.1467-6494.2009.00599.x.

59. Wager TD, Atlas LY, Lindquist MA, Roy M, Woo CW, Kross E. An fMRI-based neurologic signature of physical pain. N Engl J Med. 2013;368(15):1388-97. https://doi.org/10.1056/ NEJMoa1204471.

60. Baliki MN, Petre B, Torbey S, Herrmann KM, Huang L, Schnitzer $\mathrm{TJ}$, et al. Corticostriatal functional connectivity predicts transition to chronic back pain. Nat Neurosci. 2012;15(8):1117-9. https:// doi.org/10.1038/nn.3153.

61. Hashmi JA, Baliki MN, Huang L, Baria AT, Torbey S, Hermann $\mathrm{KM}$, et al. Shape shifting pain: chronification of back pain shifts brain representation from nociceptive to emotional circuits. Brain : a Journal of Neurology. 2013;136(Pt 9):2751-68. https://doi.org/ 10.1093/brain/awt211.

62. Denk F, McMahon SB, Tracey I. Pain vulnerability: a neurobiological perspective. Nat Neurosci. 2014;17(2):192-200. https:// doi.org/10.1038/nn.3628.

63. Rhudy JL, Williams AE, McCabe KM, Nguyen MA, Rambo P. Affective modulation of nociception at spinal and supraspinal levels. Psychophysiology. 2005;42(5):579-87. https://doi.org/10. 1111/j.1469-8986.2005.00313.x.

64. Roy M, Piche M, Chen JI, Peretz I, Rainville P. Cerebral and spinal modulation of pain by emotions. Proc Natl Acad Sci U S A. 2009;106(49):20900-5. https://doi.org/10.1073/pnas. 0904706106.

65. Jennings EM, Okine BN, Roche M, Finn DP. Stress-induced hyperalgesia. Prog Neurobiol. 2014;121:1-18. https://doi.org/10. 1016/j.pneurobio.2014.06.003.

66. Steptoe A, O'Donnell K, Badrick E, Kumari M, Marmot M. Neuroendocrine and inflammatory factors associated with positive affect in healthy men and women: the Whitehall II study. Am J Epidemiol. 2008;167(1):96-102. https://doi.org/10.1093/aje/ kwm252.

67. Uceyler N, Rogausch JP, Toyka KV, Sommer C. Differential expression of cytokines in painful and painless neuropathies. Neurology. 2007;69(1):42-9. https://doi.org/10.1212/01.wnl. 0000265062.92340.a5.

68. Watkins LR, Maier SF, Goehler LE. Immune activation: the role of pro-inflammatory cytokines in inflammation, illness responses and pathological pain states. Pain. 1995;63(3):289-302.
69. Sommer C, Kress M. Recent findings on how proinflammatory cytokines cause pain: peripheral mechanisms in inflammatory and neuropathic hyperalgesia. Neurosci Lett. 2004;361(1-3):184-7. https://doi.org/10.1016/j.neulet.2003.12.007.

70. Felger JC, Li Z, Haroon E, Woolwine BJ, Jung MY, Hu X, et al. Inflammation is associated with decreased functional connectivity within corticostriatal reward circuitry in depression. Mol Psychiatry. 2016;21(10):1358-65. https://doi.org/10.1038/mp. 2015.168.

71. Garland EL, Fredrickson B, Kring AM, Johnson DP, Meyer PS, Penn DL. Upward spirals of positive emotions counter downward spirals of negativity: insights from the broaden-and-build theory and affective neuroscience on the treatment of emotion dysfunctions and deficits in psychopathology. Clin Psychol Rev. 2010;30(7):849-64. https://doi.org/10.1016/j.cpr.2010.03.002.

72. Fredrickson BL. The role of positive emotions in positive psychology. The broaden-and-build theory of positive emotions. Am Psychol. 2001;56(3):218-26.

73. Fredrickson BL, Branigan C. Positive emotions broaden the scope of attention and thought-action repertoires. Cogn Emot. $2005 ; 19(3): 313-32$. https://doi.org/10.1080/ 02699930441000238 .

74. Wadlinger HA, Isaacowitz DM. Positive mood broadens visual attention to positive stimuli. Motiv Emot. 2006;30(1):87-99. https://doi.org/10.1007/s11031-006-9021-1.

75. Pincus T, Morley S. Cognitive-processing bias in chronic pain: a review and integration. Psychol Bull. 2001;127(5):599-617.

76. Flink IK, Smeets E, Bergbom S, Peters ML. Happy despite pain: pilot study of a positive psychology intervention for patients with chronic pain. Scand J Pain. 2015;7:71-9. https://doi.org/10.1016/ j.sjpain.2015.01.005.

77. White DK, Keysor JJ, Neogi T, Felson DT, LaValley M, Gross $\mathrm{KD}$, et al. When it hurts, a positive attitude may help: association of positive affect with daily walking in knee osteoarthritis. Results from a multicenter longitudinal cohort study. Arthritis Care \& Research. 2012;64(9):1312-9. https://doi.org/10.1002/acr.21694.

78. Vlaeyen JW. Learning to predict and control harmful events: chronic pain and conditioning. Pain. 2015;156(Suppl 1):S86-93. https://doi.org/10.1097/j.pain.0000000000000107.

79. Rescorla RA, Wagner AR. A theory of Pavlovian conditioning: variations in the effectiveness of reinforcement and non-reinforcement. In: Black H, Prokasy WF, editors. Classical conditioning II: current research and theory. New York: Appleton-Century-Crofts; 1972. p. 64-99.

80. Craske M, Hermans D, Vansteenwegen D. Fear and learning. From basic processes to clinical applications. Washington, DC: American Psychological Association; 2006.

81. Grillon C. Associative learning deficits increase symptoms of anxiety in humans. Biol Psychiatry. 2002;51(11):851-8. https://doi. org/10.1016/S0006-3223(01)01370-1.

82. Meulders A, Harvie DS, Bowering JK, Caragianis S, Vlaeyen JWS, Moseley GL. Contingency learning deficits and generalization in chronic unilateral hand pain patients. J Pain. 2014;15(10): 1046-56. https://doi.org/10.1016/j.jpain.2014.07.005.

83. Meulders A, Jans A, Vlaeyen JW. Differences in pain-related fear acquisition and generalization: an experimental study comparing patients with fibromyalgia and healthy controls. Pain. 2015;156(1):108-22. https://doi.org/10.1016/j.pain. 0000000000000016

84. Meulders A, Meulders M, Stouten I, De Bie J, Vlaeyen JWS. Extinction of fear generalization: a comparison between fibromyalgia patients and healthy control participants. J Pain. 2017;18(1): 79-95. https://doi.org/10.1016/j.jpain.2016.10.004.

85. Jenewein J, Moergeli H, Sprott H, Honegger D, Brunner L, Ettlin $\mathrm{D}$, et al. Fear-learning deficits in subjects with fibromyalgia syndrome? Eur J Pain. 2013;17:1374-84. 
86. Geschwind N, Meulders M, Peters ML, Vlaeyen JW, Meulders A. Can experimentally induced positive affect attenuate generalization of fear of movement-related pain? J Pain. 2015;16(3):258-69. https://doi.org/10.1016/j.jpain.2014.12.003. Experimental account for the influence of positive affect on fear generalization.

87.• Zbozinek TD, Craske MG. The role of positive affect in enhancing extinction learning and exposure therapy for anxiety disorders. Journal of Experimental Psychopathology. 2017;8(1):13-39. Elegant review on positive affect and fear learning.

88. Vlaeyen JWS, Morley SJ, Linton SJ, Boersma K, de Jong J. Painrelated fear: exposure-based treatment for chronic pain. Seattle: IASP press; 2012.

89. Meulders A, Meulders M, Vlaeyen JW. Positive affect protects against deficient safety learning during extinction of fear of movement-related pain in healthy individuals scoring relatively high on trait anxiety. J Pain. 2014;15(6):632-44. https://doi.org/ 10.1016/j.jpain.2014.02.009.

90. Zbozinek T, Craske MG. Positive affect predicts less reacquisition of fear: relevance for long-term outcomes of exposure therapy. Cognit Emot. 2017;31(4):712-25. https://doi.org/10.1080/ 02699931.2016 .1142428$.

91. Zbozinek TD, Holmes EA, Craske MG. The effect of positive mood induction on reducing reinstatement fear: relevance for long term outcomes of exposure therapy. Behav Res Ther. 2015;71:6575. https://doi.org/10.1016/j.brat.2015.05.016.

92. Bolier L, Haverman M, Westerhof GJ, Riper H, Smit F, Bohlmeijer E. Positive psychology interventions: a metaanalysis of randomized controlled studies. BMC Public Health. 2013;13:119. https://doi.org/10.1186/1471-2458-13-119.
93. Peters ML, Flink IK, Boersma K, Linton SJ. Manipulating optimism: can imagining a best possible self be used to increase positive future expectancies? J Posit Psychol. 2010;5(3):204-11. https://doi.org/10.1080/17439761003790963.

94. Carson JW. Loving-kindness meditation findings not related to baseline differences. J Holist Nurs. 2006;24(1):5-6. https://doi. org/10.1177/0898010105284538.

95. Seligman ME, Steen TA, Park N, Peterson C. Positive psychology progress: empirical validation of interventions. Am Psychol. 2005;60(5):410-21. https://doi.org/10.1037/0003-066X.60.5.410.

96. Batink T, Peeters F, Geschwind N, van Os J, Wichers M. How does MBCT for depression work? Studying cognitive and affective mediation pathways. PLoS One. 2013;8(8):e72778. https:// doi.org/10.1371/journal.pone.0072778.

97. Veehof MM, Oskam MJ, Schreurs KM, Bohlmeijer ET. Acceptance-based interventions for the treatment of chronic pain: a systematic review and meta-analysis. Pain 2011;152(3):533-42. doi:https://doi.org/10.1016/j.pain.2010.11.002.

98. George SZ, Robinson ME. Preference, expectation, and satisfaction in a clinical trial of behavioral interventions for acute and subacute low back pain (NCT00373867). The Journal of Pain : Official Journal of the American Pain Society. 2010;11(11): 1074-82. https://doi.org/10.1016/j.jpain.2010.02.016.

99. Carver CS, Scheier MF. Optimism. In: Snyder CR, Lopez SJ, editors. Handbook of positive psychology. New York: Oxford University Press; 2005. p. 231-43.

100. Ek J-W, van Gijn JC, Samwel H, van Egmond J, Klomp FPAJ, van Dongen RTM. Pain exposure physical therapy may be a safe and effective treatment for longstanding complex regional pain syndrome type 1: a case series. Clin Rehabil. 2009;23(12):1059-66. https://doi.org/10.1177/0269215509339875. 